\title{
The Effect of Achievement Goal Orientation on the Self-management of College Judo Athletes
}

\author{
Sungbae Park ${ }^{1 *}$
}

${ }^{1}$ Yongin University, Yongin, Korea

Received: October 16, 2018

Accepted: October 29, 2018

Published online: October 31, 2018

\section{Keywords:}

Body-care

Interpersonal management

Judo-player

Metal-management

Training-management

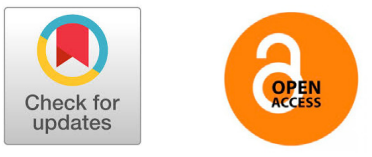

\begin{abstract}
OBJECTIVES Primary purpose of current research was to examine effect of goal orientation tendency on self control.

METHODS Among 2018 college athlets of Korea Judo Association, participants were recruited through convinence sampling. Except for insincere replies, 215 replies were analyzed for the study. Effect of achivement goal orientation of college athletes was examined throuhgh multiple regression. path analysis with Structured equation model was applied to analyze structural relationship between achievement goal orientation and self control of college athletes, which is the main purpose of this study

RESULTS At first, current research found that ego-orientation tendency and task orientation tendency have a positive effect on interpersonal relationship. Secondly, ego orientation tendency and task orientation tendency have a positive effect on psychological management of college athletes. Third, for physical management, task orientation tendency had a positive effect while it did not show significant effct on training management. Finally, as a result of analyzing structural relationship between achievement goal orientation tendency and self control, current study found that ego orientation tendency had positive effct only for interpersonal and psychological management. Task orientation tendency positively affect interpersonal, psychological, physical, and training management.

CONCLUSIONS This research found significant evidence that task orientation tendency, among achievement goal orientation, positively affect self control strategy of college Judo athletes. Task orientation tendency needs to be considered to enhance athletes ' performance during coaching.
\end{abstract}

( ) The Asian Society of Kinesiology and the Korean Academy of Kinesiology

서론

운동선수의 심리적 상태는 경기력과 밀접한 관계를 보 이며 시합까지 안정적 심리상태를 유지하기 위하여 선수 들에게 자기관리가 요구되고 있다. 이처럼 현대사회에서 는 선수가 시합에서 최고의 경기력을 발휘할 수 잇도록 신 체.정신적으로 최상의 상태를 유지하기 위한 전략으로 자

*Correspondence: Sungbae Park, Yong in, University, 134 chooin-gu, yongin-si, Gyeonggi-do, Korea.

E-mail:judo911@hanmail.net
기관리가 다루어지고 있다. 그 외에도 선수들의 스트레스 를 감소 및 선수의 일탈을 통제하도록 하는 등의 수단으로 선수코칭에 활용되고 있다[1].

이처럼 과학이 발전하면서 선수들의 경기력 강화를 위 한 훈련에는 신체요소와 더불어 심리적 상태를 모두 고려 하고 있다. 선수는 상대선수와 경쟁에서 우위를 선점하기 위해 고된 훈련에 임하며, 훈련을 인내하여 신체적.정신 적으로 강화되는 과정을 거친다[2]. 선수에 게 훈련은 일정 한 시간에서만 한정적으로 이루어지는 것이 아니다. 정해 진 훈련시간 외에 모든 일상생활에서도 선수는 스스로 자 신의 행동을 통제하고 조절해야만 보다 효과적으로 훈련 
의 성과에 도달할 수 있으며, 자신이 설정한 목표를 성취 하게 된다. 즉, 정해진 훈련 시간 외에도 자신의 부족한 점 을 보완하기 위한 개인훈련, 타인과의 원활한 관계를 위 한 노력, 자신의 컨디션과 신체적 균형을 위한 노력들이 모두 자기관리이며 선수의 목표를 달성하기 위한 전략이 될 수 있다. 이처럼 일상생활에서 자신에게 부정적인 영 역을 사전에 차단하기 위하여 스스로 자신의 행동을 통제 하고 조절하는 것이 자기관리이며[3], 자기관리가 철저한 선수일수록 높은 경기력을 보인다[4].

철저한 자기관리를 위해서는 개인의 행동을 스스로 조 절하고 제어하며 통제할 수 있도록 하는 의지가 필요하 다. 선수의 의지력은 선수의 성향에 의해서 설정된 목표 를 이루고자 하는 태도에 의해서 나타난다. 계획행동이론 (theory of planned behavior)에 따르면, 개인의 행동은 행위 의 의도에 의해서 나타날 수 있으며, 행동의도는 타인의 평가에 의한 주관적 규범과 자신의 행동에 대한 개인적 신념에 의해서 형성될 수 있다 [5]. 이처럼 개인이 이루고 자 하는 목표에 대하여 성취하고자 하는 성향에 따른 개 인의 신념은 자신을 조절하고 제어하며 통제하는 자기관 리의 행동과 관계를 보이게 된다. 훈련 시 선수가 설정한 목표에 의해서 나타나는 개인의 태도는 정서적 사고에 영 향을 미칠 수 있으며[6], 훈련참여 자세 및 행동에도 영향 을 미치게 된다. 결과적으로 자기조절과 통제를 위한 행 동의지를 변화시킬 수 있다.

선수의 성향에 의해서 설정된 목표를 성취하기 위한 선수의 태도 및 자세가 성취목표성향이며, 자신의 능력 을 보여 타인에 게 자신의 유능감과 능력을 입증하여 보이 려는 성향으로 볼 수 있으며, 이를 이분화 하여 자아지향 성향과 과제지향성향으로 구분할 수 있다[7]. 이와 같은 성취목표성향은 선수의 심리적 성향으로 볼 수 있으며, 선수의 일상생활에서 의지를 갖고 행동을 조절하며 통제 하는 자기관리와도 밀접한 관련을 갖게 된다고 사료된다.

선행연구에서도 스포츠 선수들의 성취목표성향은 스 스로의 행동을 조절하고 통제하는 자기관리능력과 밀접 한 관계를 보인다고 보고하고 있다. 이처럼 스포츠 종목 을 불문하고 선수들의 자기관리능력과 선수의 개인적인 성향인 성취목표성향은 밀접한 관계를 보인다는 것을 알 수 있다.

이상의 내용을 살펴보았을 때, 대학유도선수들의 경기 력 향상을 위해서는 선수들의 자기관리 전략이 필요하며, 이를 위한 연구가 필요하다고 사료된다. 그 외에도 선수
들의 경기력 향상을 위하여 다양한 연구가 활성화를 띄고 있으나, 경기력이란 시합상황에서 발휘되는 것으로 사전 에 측정하기란 쉽지 않다는 한계를 갖는다. 오히려 선수 들의 경기력과 직접적인 관계를 갖는다는 자기관리를 살 펴보는 것이 경기력 향상을 위한 연구에 보다 적합하다 고볼 수 있다.

즉, 선수의 개인적 성향에 의해서 설정된 목표를 이루 고자 하는 태도는 성취목표성향으로써, 훈련 시 선수의 훈련자세에만 영향을 미치는 것이 아닌, 선수의 일상생 활에서 이루어지는 자기관리에도 영향을 미치게 된다[8]. 선수의 심리적 상태는 선수의 훈련성과 및 경기력 향상 등에 있어서 주요한 요소이다. 따라서 선수의 경기력뿐만 아니라 선수의 발전을 위해서는 신체적 훈련만큼이나 정 서적 관리가 동시에 이루어져야 한다. 특히, 승부에 있어 심리적 상태가 중요한 유도종목에서는 정서적 관리가 매 우 중요하다[9]. 이러한 정서적 관리를 바탕으로 하여 선 수는 일상생활을 통제하고 조절하도록 하는 자기관리 전 략이 수행될 시 보다 안정된 심리적 상태를 유지하여 경 기에서 효과적인 경기력을 보일 수 있도록 할 수 있을 것 이라고 사료된다.

따라서 본 연구에서는 대학유도선수들의 성취목표성 향과 자기관리의 관계를 살펴봄으로써 대학유도선수의 경기력 향상을 위한 기초자료를 제공하는데 연구의 의의 를 둔다.

\section{연구 방법}

\section{연구대상 및 자료수집}

연구의 목적을 규명하기 위하여 <figure 1>과 같은 연구 의 모형을 구형하였다.

연구모형에 따른 변수 간의 관계를 살펴보기 위하여

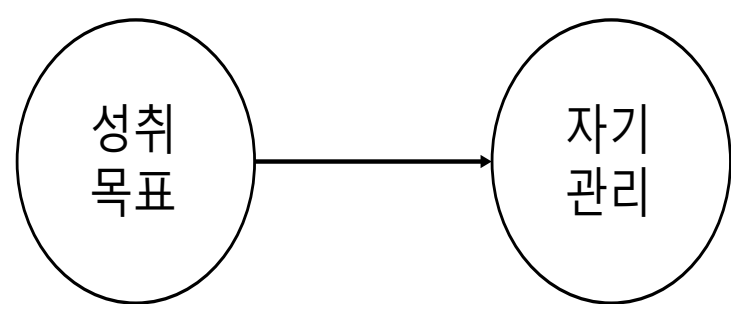

Figure 1. Research model design 
Table 1. General characteristics of the study participants(n:215)

\begin{tabular}{|c|c|c|c|c|}
\hline \multicolumn{2}{|c|}{ Group } & \multirow{2}{*}{$\frac{N}{144}$} & \multirow{2}{*}{$\begin{array}{c}\text { Frequency } \\
66.98\end{array}$} & \multirow{2}{*}{$\begin{array}{c}\text { Cumulative Frequency (\%) } \\
66.98\end{array}$} \\
\hline Gender & male & & & \\
\hline Gender & female & 71 & 33.02 & 100.00 \\
\hline \multirow{4}{*}{ Grade } & 1 grade & 76 & 35.35 & 35.35 \\
\hline & 2 grade & 59 & 27.44 & 62.79 \\
\hline & 3 grade & 58 & 26.98 & 89.77 \\
\hline & 4 grade & 22 & 10.23 & 100.00 \\
\hline \multirow{4}{*}{ career } & 0 & 21 & 9.77 & 9.77 \\
\hline & $1 \sim 2$ & 45 & 20.93 & 30.70 \\
\hline & $3 \sim 4$ & 34 & 15.81 & 46.51 \\
\hline & $5 \sim$ & 115 & 53.49 & 100.00 \\
\hline
\end{tabular}

2017년 대한유도회에 등록된 대학유도선수를 모집단으 로 설정하였다. 표본추출방법으로는 편의표본추출방법 (Convenience sampling)을 실시하였고, 230명의 대학유도 선수를 대상으로 설문조사를 실시하였다. 회수된 230 부 의 설문지 중 누락되었거나 불성실하다고 판단되는 15 부 를 제외하고 215 부를 최종분석에 활용하였다. 일반적 특 성에 따른 자료의 분포로는 <Table 1>과 같다.

<Table 1>과 같이 설문조사에 응답한 조사대상자의 일반적 특성에 따른 분포로는 남자대학유도선수 144 명 (66.98\%), 여자대학유도선수 71명(33.02\%)이며, 학년에 따 라서는 1학년 76명(35.35\%), 2학년 59명(27.44\%), 3학년 58 명(26.98\%), 4학년 22명(10.23\%)으로 나타났다. 입상경력 에 따라서는 1 회에서 2 회 45 명(20.93\%), 3 회에서 4 회 34 명 (15.81\%), 5회 이상 115 명(53.49\%), 입상경험이 없는 대학 유도선수 21 명(9.77\%)으로 나타났다.

\section{측정도구}

연구에서 활용된 조사도구는 설문지이며, 설문지는 선 행연구에서 충분히 타당성과 신뢰성이 확인된 것을 활용 하였다. 이후 체육학 박사학위 소지자 3 인으로 구성된 전 문가 회의를 통하여 설문문항을 연구의 목적에 맞도록 수 정 및 보완의 과정을 거쳤다.

이후 측정도구의 구성타당도(Construct validity)를 살 펴보기 위하여 탐색적 요인분석을 실시하였다. 탐색적 요인분석 방법으로는 다음과 같다. 개념을 도출하기 위 하여 주성분분석을 실시한 후 직각회전방식인 베리맥스 를 실시하였다. 고유값의 기준은 1.0 이상으로 하였으며, 요인적재값은 0.5 이상으로 하였다. 측정문항의 내적일치 도를 살펴보기 위하여 신뢰도분석을 실시하였으며, 기준
으로는 0.7 이상으로 하였다. 구체적으로는 다음과 같다.

성취목표성향 대학유도선수의 성취목표성향은 Duda, Nicholls(1989)가 개발하고 Sung(1995)이 번안하여 Choi, $\mathrm{Bea}$ (2006), Cho, Kim, Park(2015)의 연구에서 사용된 설문 지를 활용하였다. 성취목표성향은 자아지향성향(문항), 과제지향성향(문항)의 2 개의 하위요인으로 구성되었으 며, 13 문항으로 구성되었다. 정의 범주는 Likert Scale 5점 척도(1점=전혀 아니다, 5 점=매우 그렇다) 형식으로 반응 하도록 구성되었다. 성취목표성향의 구성타당도를 살펴 보기 위하여 탐색적 요인분석과 신뢰도분석을 실시한 결 과 <Table 2>와 같이 나타났다.

factor1은 고유값 3.02589로 나타났으며, factor2는 고유 값 2.67658 로 모두 1 이상의 고유값을 갖는 것으로 나타났 다. 따라서 factor1을 ‘자아지향성향', factor2를 '과제지향 성향'으로 명명하였다. 구성타당도를 살펴보기 위하여 문항별 적재된 값을 살펴본 결과 적재값의 문제가 있는 자아지향성향의 1 번 문항, 과제지향성향의 7 번 문항, 8 번 문항, 9 번 문항을 삭제 후 재분석을 실시하였다. 결과, 자 아지향성향, 과제지향성향 모두 .6이상의 적재값을 상회 하는 것으로 나타났고, 구형검증결과도 .779로 나타나면 서 표집크기도 이상적인 것으로 나타났다. 누적설명도 $63.36 \%$ 의 설명력을 보이는 것으로 나타나면서 구성타당 도가 확보되었다고 판단된다.

이후 측정문항간의 내적일치도를 살펴보기 위하여 신 뢰도분석을 실시한 결과 <Table 2>에 나타난 바와 같이 ' $\alpha$ ' 값은 자아지향성향 .8290 , 과제지향성향 .8098 로 나타났 다. ' $\alpha$ ' 값 모두 .6이상을 상회하는 것으로 나타나 내적일 치도도 확보되었다. 
Table2 Reliability and validity analysis of achievement goal orientation

\begin{tabular}{cccc}
\hline & $\begin{array}{c}\text { factor loading } \\
\text { factor1 }\end{array}$ & $\begin{array}{c}\text { factor2 } \\
\text { (Self-oriented propensity) }\end{array}$ & Uniqueness \\
\hline (Task orientation) & 0.2702 \\
x_5 & 0.8495 & 0.0903 & 0.341 \\
x_2 & 0.8058 & 0.0987 & 0.3439 \\
x_3 & 0.7874 & 0.1901 & 0.4442 \\
x_6 & 0.7393 & -0.0963 & 0.5031 \\
x_12 & 0.6241 & 0.3277 & 0.3019 \\
x_10 & 0.1185 & 0.8271 & 0.3478 \\
x_11 & 0.088 & 0.8028 & 0.3576 \\
x_13 & -0.0419 & 0.8004 & 0.3878 \\
Egen-values & 0.2748 & 0.7326 & KMO $=0.779$ \\
Vari.(\%) & 3.02589 & 2.67658 & chi-square \\
Cum.(\%) & 33.62 & 29.74 & 777.719 \\
Cronbach's 'a' & 33.62 & 63.36 & df:36 \\
total cronbach's 'a' & .8290 & .8092 & $p=.001$ \\
\hline
\end{tabular}

Table 3 Reliability and validity analysis of self-management

\begin{tabular}{|c|c|c|c|c|c|}
\hline & \multicolumn{4}{|c|}{ factor loading } & \multirow[b]{2}{*}{ Uniqueness } \\
\hline & $\begin{array}{c}\text { factor1 } \\
\text { (Interpersonal) }\end{array}$ & $\begin{array}{c}\text { factor2 } \\
\text { (Mental) }\end{array}$ & $\begin{array}{l}\text { factor3 } \\
\text { (Body) }\end{array}$ & $\begin{array}{c}\text { factor4 } \\
\text { (Training) }\end{array}$ & \\
\hline x_12 & 0.8294 & 0.0465 & 0.1322 & -0.0709 & 0.2875 \\
\hline x_2 & 0.7812 & -0.006 & 0.0913 & 0.2134 & 0.3359 \\
\hline x_17 & 0.7256 & 0.36 & -0.0375 & 0.1594 & 0.3171 \\
\hline x_15 & 0.7071 & 0.0697 & 0.0549 & 0.061 & 0.4884 \\
\hline x_10 & 0.6814 & 0.1671 & 0.306 & 0.1243 & 0.3987 \\
\hline$x \_8$ & 0.0758 & 0.8391 & 0.1714 & 0.2307 & 0.2076 \\
\hline$x \_7$ & 0.0687 & 0.8154 & 0.3152 & 0.1811 & 0.1983 \\
\hline x_14 & 0.0782 & 0.7789 & 0.1503 & -0.2066 & 0.322 \\
\hline x_4 & 0.2077 & 0.6961 & -0.0036 & 0.2117 & 0.4274 \\
\hline x_16 & 0.2873 & 0.2724 & 0.7283 & 0.0754 & 0.3072 \\
\hline x_11 & 0.2527 & 0.1718 & 0.7262 & 0.1039 & 0.3685 \\
\hline x_9 & -0.1041 & 0.0825 & 0.6582 & 0.3103 & 0.4528 \\
\hline$x \_6$ & 0.0523 & 0.0592 & 0.1703 & 0.8326 & 0.2715 \\
\hline x_1 & 0.2153 & 0.2422 & 0.1758 & 0.8113 & 0.2058 \\
\hline x_18 & 0.4458 & 0.0707 & 0.3957 & 0.5979 & 0.3917 \\
\hline Egen-values & 3.25363 & 2.80243 & 1.98262 & 1.98098 & $\mathrm{KMO}=0.785$ \\
\hline Vari.(\%) & 21.69 & 18.68 & 13.22 & 13.21 & chi-square \\
\hline Cum.(\%) & 21.69 & 40.37 & 53.59 & 66.80 & 1534.115 \\
\hline $\begin{array}{l}\text { Cronbach's ' } a \text { ' } \\
\text { total cronbach's ' } a \text { ' }\end{array}$ & .8344 & .8355 & .6567 & .7529 & $\begin{array}{l}d f: 105 \\
p=.001\end{array}$ \\
\hline
\end{tabular}

자기관리 대학유도선수들의 자기관리를 측정하기 위 한 측정도구로는 $\mathrm{Heo}$ (2003)이 개발한 자기관리 설문지 를 Kong, Kim (2017)의 연구에서 사용한 척도를 활용하였 다. 자기관리 설문지는 대인, 정신, 훈련, 몸으로 4 개의 하
위요인으로 이루어졌으며, 총 18 문항을 구성되었으며 범 주는 Likert Scale 5점 척도(1점=전혀 아니다, 5점=매우 그 렇다) 형식으로 반응하도록 구성되었다. 자기관리의 구 성타당도를 살펴보기 위하여 탐색적 요인분석과 신뢰도 
분석을 실시한 결과 <Table $3>$ 과 같이 나타났다.

요인별 고유값으로 factor1 3.02589, factor2 2.80243, factor3 1.98262, factor4 1.98098 로 나타났으며, 모두 1 이상의 고유값을 갖는 것으로 나타났다. factor1을 ‘대인 관리', factor2를 ‘정신관리’ factor3 '몸 관리’, factor4 ‘훈련관리’로 명 명하였다. 측정문항 간의 구성타당도를 살펴보기 위하여 문항별 적재된 값을 살펴본 결과 몸 관리의 5 번, 13 번, 훈 련 3문항의 값의 문제가 있는 것으로 나타나 삭제 후. 재 분석을 실시한 결과, 대인관리, 정신관리, 몸관리, 훈련관 리 모두 .5 이상의 적재값을 상회하는 것으로 나타났다. 구 형검증결과 .785로 나타나면서 표집크기도 이상적인 것 으로 볼 수 있으며, 누적설명도 $66.80 \%$ 의 설명력을 보이 는 것으로 나타나 구성타당도가 확보되었다고 판단된다.

측정문항간의 내적일치도를 살펴보기 위하여 신뢰도 분석을 실시한 결과, <Table $3>$ 에 나타난 바와 같이, ' $\alpha$ '값 은 대인관리 .8344 , 정신관리 .8355, 몸관리 .6567, 훈련관 리 .7529로 나타나면서 ' $\alpha$ ' 값이 모두 .6이상의 값을 상회 하는 것으로 나타났다. 따라서 측정문항 간의 내적일치 도도 확보되었다.

\section{자료 산출 및 분석}

본 연구는 'STATA 14.0 Ver.'을 이용하여 연구목적에 따 라 분석을 실시하였다. 첫째, 조사대상자의 특성을 살펴 보기 위하여 빈도분석을 실시하였다. 둘째, 측정도구의 구성타당도와 신뢰도를 살펴보기 위하여 탐색적 요인 분석(Exploratory Factor Analysis)과 신뢰도분석(reliability analysis)를 실시하였다. 셋째, 대학유도선수의 성취목표 성향이 자기관리에 미치는 영향을 살펴보기 위하여 다중 회귀분석을 실시하였으며, 성취목표성향이 자기관리의 하위요인인 대인관리, 정신관리, 몸관리, 훈련관리에 대 한 경로관계를 살펴보기 위하여 경로분석(path analysis) 을 실시하였다.

\section{결과}

\section{대학유도선수의 성취목표성향과 자기관리}

대학유도선수의 성취목표성향이 자기관리에 미치는 영향을 살펴보기 위하여 다중회귀분석과 경로분석을 실 시하였다. 실시한 결과 <Table $4>$, <Table 5>과 같이 나타 났다.

\section{성취목표성향이 대인관리에 미치는 영향}

성취목표성향이 자기관리의 정신관리에 미치는 영향 을 살펴보기 위하여 다중회귀분석을 실시한 결과 < Table4>에 나타난 바와 같이, 성취목표성향의 자아지향 성향(beta:27807, $\beta: 2542^{* * *}$ t: 3.91)이 정신관리에 정 $(+)$ 적인 영향을 미치는 것으로 나타났으며, 과제지향성향 (beta:.3426., $\beta: 2772^{* * *}$, $t$ 4.27)도 정신관리에 정(+)적인 영 향을 미치는 것으로 나타났다. 다중회귀분석 결과 모두 통계적으로 유의미한 것으로 나타났다. 회귀계수를 비교 한 결과 과제지향성향이 정신관리에 높은 영향력을 보이 는 것으로 나타났다. 또한, 회귀식의 설명도 $18.35 \%$ 를 보 이는 것으로 나타났다. F값이 23.82로 나타나면서 이와 같 은 회귀식도 유의미한 것으로 나타났다.

\section{성취목표성향이 몸 관리에 미치는 영향}

성취목표성향이 자기관리의 몸 관리에 미치는 영향 을 살펴보기 위하여 다중회귀분석을 실시한 결과 < $<a-$ ble $4>$ 에 나타난 바와 같이, 성취목표성향의 자이지향성 향(beta:.0359, $\beta: .0345, \mathrm{t}: 0.50)$ 이 몸 관리에 정 $(+)$ 적인 영향 을 미치는 것으로 나타났으나 통계적으로 유의하지는 않 은 것으로 나타났다. 과제지향성향(beta:.2841, $\beta: 2413^{\star * *}$, $\mathrm{t}: 3.47)$ 은 정(+)적인 영향을 미치는 것으로 나타났고 통계 적으로도 유의미한 것으로 나타났다. 회귀계수를 비교한 결과 과제지향성향이 몸관리에 높은 영향력을 보이는 것 으로 나타났다. 또한, 회귀식의 설명도 $6.44 \%$ 를 보이는 것 으로 나타났다. F값이 7.30로 나타나면서 위와 같은 회귀 식도 유의미한 것으로 나타났다.

\section{성취목표성향이 훈련관리에 미치는 영향}

성취목표성향이 자기관리의 몸 관리에 미치는 영향 을 살펴보기 위하여 다중회귀분석을 실시한 결과는 $<\mathrm{Ta}-$ ble4>에 나타난 바와 같이, 성취목표성향의 자아지향성 향(beta:.1357, $\beta: 1232$, t: 1.75)과 과제지향성향(beta:.1708, $\beta: 1372, \mathrm{t}: 1.95)$ 이 훈련에 정(+)적인 영향을 미치는 것으로 나타났으나, 통계적으로 유의미하지 않은 것으로 나타났 다. 성취목표성향이 훈련관리에는 유의미한 영향을 보이 지 않는 것으로 나타났다. 또한, 회귀식의 설명도 $6.44 \%$ 를 보이는 것으로 나타났다. F값이 7.30로 유의미한 것으로 나타나면서 위와 같은 회귀식도 유의미한 것으로 나타났 다. 
Table 4 The effect of achievement goal orientation on self-management

\begin{tabular}{|c|c|c|c|c|c|}
\hline \multirow{2}{*}{$\begin{array}{l}\text { Dependent } \\
\text { Variable }\end{array}$} & \multirow{2}{*}{$\begin{array}{l}\text { Independent } \\
\text { Variable }\end{array}$} & \multicolumn{2}{|c|}{$\begin{array}{l}\text { Unstandardized } \\
\text { Coefficient }\end{array}$} & \multirow{2}{*}{$\begin{array}{c}\text { standardized } \\
\text { Coefficient } \\
\text { Beta }\end{array}$} & \multirow[t]{2}{*}{ t.value } \\
\hline & & $\beta$ & SE & & \\
\hline \multirow{4}{*}{ Interpersonal management } & Self-oriented propensity & $.1597^{*}$ & .0558 & .1332 & 2.38 \\
\hline & Task orientation & $.2834^{* * *}$ & .0631 & .2671 & 4.23 \\
\hline & constant & & .2597 & 2.4509 & 9.44 \\
\hline & $\mathrm{R} 2=.1328$ Radj. $=.1246 \mathrm{~F}=16.23^{* * *} \mathrm{n}=215$ & & & & \\
\hline \multirow{4}{*}{ Mental management } & Self-oriented propensity & $.2542^{* * *}$ & .0711 & .27807 & 3.91 \\
\hline & Task orientation & $.2772^{* * *}$ & .0803 & .3426 & 4.27 \\
\hline & constant & & .3304 & 1.3176 & 3.99 \\
\hline & $\mathrm{R} 2=.1835$ Radj. $=.1758 \mathrm{~F}=23.82^{* * *} \mathrm{n}=215$ & & & & \\
\hline \multirow{4}{*}{ Body-care } & Self-oriented propensity & .0345 & .0725 & .0359 & 0.50 \\
\hline & Task orientation & $.2413^{* * *}$ & .0819 & .2841 & 3.47 \\
\hline & constant & & .3369 & 2.1046 & 6.25 \\
\hline & $\mathrm{R} 2=.0644$ Radj. $=.0556 \mathrm{~F}=7.30^{* * *} \mathrm{n}=215$ & & & & \\
\hline \multirow{4}{*}{ Training management } & Self-oriented propensity & .1232 & .0774 & .1357 & 1.75 \\
\hline & Task orientation & .1372 & .0875 & .1708 & 1.95 \\
\hline & constant & & .3601 & 2.4793 & 6.88 \\
\hline & $\mathrm{R} 2=0.0441$ Radj. $=0.0351 \mathrm{~F}=4.89^{* *} \mathrm{n}=215$ & & & & \\
\hline
\end{tabular}

Table 5. Statistics of path analysis

\begin{tabular}{|c|c|c|c|c|c|}
\hline path & & & Standardization factor & Standard error & Z \\
\hline Self-oriented propensity & $\rightarrow$ & \multirow{2}{*}{ Interpersonal management } & $.1597^{*}$ & .0658 & 2.43 \\
\hline Task orientation & $\rightarrow$ & & $.2834^{* * *}$ & .0641 & 4.42 \\
\hline Self-oriented propensity & $\rightarrow$ & \multirow{2}{*}{ Mental management } & $.2542^{* * *}$ & .0627 & 4.05 \\
\hline Task orientation & $\rightarrow$ & & $.2772^{* * *}$ & .0624 & 4.44 \\
\hline Self-oriented propensity & $\rightarrow$ & \multirow{2}{*}{ Body-care } & .0345 & .0690 & 0.50 \\
\hline Task orientation & $\rightarrow$ & & $.2413^{* * *}$ & .0672 & 3.59 \\
\hline Self-oriented propensity & $\rightarrow$ & \multirow{2}{*}{ Training management } & .1232 & .0693 & 1.78 \\
\hline Task orientation & $\rightarrow$ & & $.1372^{*}$ & .0692 & 1.98 \\
\hline
\end{tabular}

\section{대학유도선수의 성취목표성향과 자기관리의 관계}

대학유도선수의 성취목표성향과 자기관리의 구조를 살펴보기 위하여 성취목표성향과 자기관리의 경로분석 을 실시한 결과<Table 5>에 나타난 바와 같이, 대학유도선 수의 성취목표성향의 하위요인인 과제지향성향은 자기 관리의 대인관리(경로계수:.2834***, 표준오차:.0641), 정 신관리(경로계수:.2772***, 표준오차:.0624), 몸 관리(경로 계수:2413***, 표준오차:.0672), 훈련관리(경로계수:.1372*, 표준오차:.0692)에 정(+)적인 영향을 미치는 것으로 나타
났다. 대학유도선수의 성취목표성향의 하위요인인 자아 지향성향은 대인관리(경로계수:1597*, 표준오차:.0658), 정신관리(경로계수:.2542***, 표준오차:.0627)에 정(+)적 인 영향을 미치는 것으로 나타났으나, 대학유도선수의 몸관리와 훈련관리에는 유의한 영향을 미치지 못하는 것 으로 나타났다.

대학유도선수의 대인관리와 정신관리에 자아지향성 향과 과제지향성향이 모두 유의한 영향을 미치는 것으로 나타났고, 경로계수를 비교한 결과 과제지향성향이 높은 
영향력을 보이는 것으로 나타났다. 반면, 몸, 훈련관리에 는 자아지향성향은 유의한 영향을 미치지 못하는 것으로 나타나면서 과제지향만이 유의미한 영향을 미치는 것으 로 나타나면서 과제지향성향은 자기관리의 모든 하위요 인에 유의한 영향을 미치는 것으로 나타났다.

\section{논의}

본 연구는 대한유도회에 등록된 대학유도선수를 대상 으로 하여 대학유도선수의 성취목표성향이 자기관리에 미치는 영향을 살펴보았다. 다음에서는 선행연구를 바탕 으로 본 연구에서 도출된 결과를 비교하여 논의를 하고 자 한다.

자기관리(Self-management)란 행동수정 분야에서 Jones, Nelson, Kazidin(1977)에 의해 자신의 행동에 변화를 주 거나 유지하도록 하기 위한 스스로의 전략이며 이를 통해 자신의 환경을 수정하면서 자신을 관리하는 것으로 제시 가 되었다. 스포츠 상황에서 자기관리란 정해진 훈련의 시간 외의 일상생활의 모든 시간에서 자신의 행동을 조절 하고 절제하여 자신의 심신의 상태를 준비하는 과정으로 써[17], 선수에게 자기관리는 중요한 전략으로 다루어진 다. 따라서 자기관리는 선수와 지도자 모두 관심을 가져 야 할 부분이다. 엘리트 선수의 자기관리전략은 인지적 행동전략으로써 선수가 인지하고 성취하고자 하는 훈련 의 목표와 목적 등과 같은 요인에 의해서 자기관리 행동 이 변화될 수 있다[18].

본 연구에서 개별적으로 가설검증을 실시한 결과 대학 유도선수의 목표성향이 자기관리에 대인관리, 정신관리 에 긍정적인 영향을 미치는 것으로 나타났고, 몸 관리에 는 과제지향성향만 유의한 영향을 미치는 것으로 나타났 다. 성취목표성향의 과제지향성향이 자아지향성향보다 자기관리에 높은 영향력을 보이는 것으로 나타났다.

이와 같이, 대학유도선수의 성취목표성향은 자기관리 의 하위요인에 부분적으로 유의한 영향을 미치는 것으로 나타나면서 선행연구와 다소 상이한 결과를 보이는 것으 로 나타났다. 하지만 대학유도선수의 자기관리에 과제지 향성향이 자아지향성향보다 높은 영향력을 보이면서 선 수들의 자아지향성향보다 과제지향성향이 자기관리와 밀접한 관계가 있다는 선행연구의 결과와 일맥상통한 결 과라고 사료된다.

따라서 대학유도선수의 자기관리능력 제고를 위해서
는 등급이나 높은 점수를 통하여 자신의 능력을 평가하고 타인과 경쟁을 통하여 자신의 우월함을 입증하려 하는 자 아지향성향보다는 운동능력 향상과 진보, 숙달을 목표로 하여 평가의 준거가 자신이 되는 과제지향성향이 대학유 도선수에 게 권장될 필요성이 있다.

즉, 대학 유도선수의 훈련목표에 대하여 인지하고 있 는 성향을 자아지향성향과 과제지향성향을 중심으로 살 펴보았을 때 운동수행능력의 향상과 노력 및 학습의 의 미를 두는 과제성향이 자아지향성보다 높은 영향력을 보 이면서 인지된 행동의 전략으로 볼 수 있는 자기관리 전 략을 높일 수 있도록 하는 주요변수라는 것을 시사한다.

자아지향성향이 자기관리에 부정적인 영향을 미치는 것이 아닌, 과제지향성향과 동일하게 자기관리에 긍정적 인 영향을 미치는 것으로 나타났다. 이와 같은 결과는 스 포츠 선수를 대상으로 한 Jung, Song, Hwang(2013)의 연구 의 결과와 유사한 것으로 상대방과 경쟁을 지향하는 스포 츠의 특성을 갖고 있는 유도종목의 대학유도선수가 타인 과의 경쟁에서 패배하지 않으려는 동기가 자기관리전략 을 높일 수 있도록 하는 것으로 해석할 수 있다. 또한, 성취 하고자 하는 목표를 회피하는 무동기적인 자세나 수동적 인 자세보다는 접근의 동기 형태를 불문하고 동기가 높은 것이 바람직할 수 있다는 것을 결과를 지지한다[20].

개인의 평가와 주관적 규범 및 인지한 행동의 조절력 등과 같은 개인의 인지적 요소 의해서 개인의 의지와 행 동으로 이어질 수 있다는 계획행동이론과 비교해보았을 때[21], 훈련의 목표, 목적, 가치에 대하여 선수가 인지하 고 있는 성향이 훈련 외의 일상생활에서 자신을 조절하고 통제하려는 자기관리에 대한 의지를 결정하여 행동전략 으로 이어질 수 있다는 것으로 볼 수 있다. 목표성향을 갖 고 있는 대학유도선수인 경우 목표와 동기가 없는 대학유 도선수보다 인지적 행동전략인 자기관리를 회피하지 않 고 적극적으로 수행할 수 있다는 것을 시사한다.

선수의 인지 행동전략인 자기관리 전략을 향상시킬 수 있도록 하는 태도와 행동을 위해서는 목표와 동기를 형성 시킬 수 있어야 하며, 선수에게 경쟁과 우월함을 목적으 로 하는 자아지향성향보다 과제지향성향을 갖고 훈련에 참여할 수 있도록 하는 인지전략프로그램 등을 구축하는 등 지도자의 관심이 필요하다는 것을 시사한다.

대학유도선수의 성취목표성향과 자기관리의 경로를 살펴본 결과에서도 과제지향성향은 자기관리의 대인관 리, 정신관리, 몸관리, 훈련관리에 모두 정(+)적인 영향을 
미치는 것으로 나타났으나, 자아지향성향은 대인관리와 정신관리에만 정 $(+)$ 적인 영향을 미치는 것으로 나타났고 과제지향성이 높은 영향력을 보이는 것으로 나타났다.

결과적으로 대학유도선수의 자기관리를 위해선 동기 가 없어서 목표에 대하여 회피적이거나 수동적인 것보다 형태를 불문하고 동기를 형성시킬 수 있어야 한다. 또한, 대학유도선수의 자기관리전략 향상을 위하여 성취목표 성향을 고려할 시 타인과 경쟁, 자신의 우월함 과시를 목 표로 하는 자아지향성향보다는 과제목표성향일 때 자기 관리 전략 제고에 보다 높은 긍정적인 효과를 보일 수 있 다는 것을 시사한다.

\section{결론}

과학이 발전하면서 엘리트선수에 대한 코칭 및 트레이 닝의 체계도 변화되고 있으며, 선수들의 심리적 상태마저 전문가에 의해 관리되고 있다. 이는 선수의 불안, 초조, 등 의 부정적인 심리상태가 선수의 경기력이나 훈련의 성과 를 감소시킬 수 있기에 이를 예방하고 조절하기 위함에 목 적이 있다.

선수들 스스로 자신의 부정적인 환경을 사전에 예방하 기 위하여 스스로 자신의 행동을 통제하고 조절하는 자기 관리 전략이 선수들의 훈련의 성과와 경기력을 높일 수 있 는 수단이 되었음에도 불구하고 대부분의 연구가 경기력 을 중심으로 이루어지고 있다. 선수의 경기력은 스포츠 경 기상황에서 나타나기에 고려해야할 변수가 상당히 존재 하기에 측정에 한계가 있다. 이러한 측정의 한계를 갖는 선수들의 경기력을 측정하고 있기에 선행연구에서는 한 계점을 제시하고 있는 실정이다. 따라서 선수들의 경기력 을 높일 수 있는 수단이 될 수 있는 전략을 모색하는 것이 더욱 바람직하다.

본 연구에서 이와 같은 전략의 일부인 자기관리에 관한 실증적 분석을 실시하였으며, 자기관리 전략에 선수들의 목표에 대한 태도가 미치는 영향을 살펴봄으로서 선수들 의 성향과 자기관리의 관계를 살펴보았다. 선수들이 훈련 에 참여하는 목적과 성취하고자 하는 목표에 대한 개인의 성향은 개인 스스로 통제하고 조절해야 하는 자기관리에 영향을 미치는 선행변수로 나타났다. 선수 스스로가 자기 관리 전략을 지속적으로 실천할 수 있도록 하기 위해서는 선수 개인적인 성향마저 파악할 수 있도록 지도자가 관심 을 가져야 할 필요를 보여준다.
자기관리 전략이란 스스로 자신의 환경과 행동을 통제 하고 조절하는 행위로써 개인의 의지에 의한 행동으로 볼 수 있다. 개인의 행동의지는 자신의 앞선 행동을 평가하거 나자신의 신념에 의해 형성되는 행동에 대한 태도와 타인 의 평가 또는 의견에 의한 주관적 규범에 의해서 결정될 수 있다. 향후에는 개인적 성향만이 아닌 개인의 의도를 결정지을 수 있는 다양한 변수를 고려한 연구가 진행될 때 보다 의미있는 결과를 얻을 수 있을 것이라고 사료된다.

그럼에도 불구하고 본 연구에서는 선수들의 경기력 향 상을 위한 연구를 진행함에 있어 환경적인 제약요소가 많 을뿐더러 경기순간에 나타남으로써 측정에 한계를 보이 는 경기력을 조사한 것이 아닌, 경기력 향상의 전략이 될 수 있는 자기관리를 중심으로 하여 경기력 향상에 관한 기 초적 연구를 실시하였다는데 그 의의를 둔다.

\section{Conflicts of Interest}

The authors declare no conflict of interest.

\section{References}

1. Lee JH, Kang HS. The Relationship among self-management, stress and deviant behavior of judo athletes. J Coaching Dev, 2015; 17(3):189-196.

2. Kong Sb. The structural relationship between judo player's competing spirit, exercise flow, and satisfaction. J Korean Alliance Martial Arts, 2016; 18(4):79-90.

3. Jones RT, Nelson RE, Kazdin AE. The role of external variables in self reinforcement: A review. Behav Modif, 1977; 1:147-178.

4. Woo SB. The causal relationship among mental strength, self-management, confidence and performance of golf player [doctoral dissertation]. University of Dae-gu; 2015

5. Ajzen I. The theory of planned behavior. Organ Behav Hum Decis Processes. 1991; 50:179-211.

6. Burton D. Evaluation of goal setting training on selected cognitions and performance of collegiate swimmers [doctoral dissertation]. University of Illinois; 1983

7. Duta JL. Goal perspectives, participation and persistence in sport. International J Sport Psychol. 1989; 20:42-56. 
8. Nam IS, Kim MM. The effect of achievement goal orientation on self-management and performance strategy of middle and high school kumdo players. J Korean Phys Educ Sport Girls Women, 2010; 24(2):193-205.

9. Jeon KY. The effect of self-confidence and stress on university judo athletes performance. J Digit Convergence. 2016; 14(12):545-553

10. Duta JL, Nicholls. JG. The task and ego orientation in sport questionnaire: psychometric properties. Unpublished manuscript. J Appl psychol. 1989; 14:172-204.

11. Sung CH. The effects of achievement goal orientations and goal-setting styles on motivational behaviors and performance [doctoral dissertation,]. University of Seoul; 1995

12. Choi JW, Bae SJ. The effect where the accomplishing target propensity of the tennis man bow goes mad to a competitive anxiety. J Sport Info Technol. 2006; 1(1):17-27.

13. Cho YC, Kim YH, Park SB. The relationship between high school judo players' achievement-goal orientation, exercise passion, and exercise flow. Korean J Sports Sci. 2015; 24(1):141-151.

14. Heo JH. Development and validation of athletes' self-man- agement questionnaire(ASMQ). Korean J Sport Psychol. 2003; 14(2): 95-109.

15. Kong SB, Kim BK. The relationship between university sireum players' sports mental power, self management and performance. Korea J Sport. 2017; 15(1):589-599.

16. Jones RT, Nelson RE, Kazdin AE. The role of external variables in self reinforcement: A review. Behav Modif. $1977 ; 147-178$.

17. Yoo J. Development of psychological skill test for Korean athletes. Korean J Sport Stud. 1996; 35(3):3107-3124.

18. Yoo J, Huh JH. The self management strategies of Korean national athletes: Qualitative research. Korean J Sport Psychol. 2004; 15(3):27-52.

19. Jeong SC, Song ES, Hwang J. Influence of mentoring and achievement goal orientation on self-management for high school soccer athletes. Kinesiol. 2013; 15(4):6373.

20. Hwang J. Self-handicapping in physical education: Implicit theory of ability and achievement goal orientation. Korean J Sport Stud. 2011; 50(1):57-69.

21. Ajzen I. The theory of planned behavior, Organ Behav Hum Decis Processes. 1991; 50:179-211. 